\title{
Pregnancy following renal transplantation in Sri Lanka
}

\author{
Chandrika N Wijeyaratne', Rezvi Sheriff', H R Seneviratne ${ }^{3}$, and A H Sheriffdeen ${ }^{4}$ \\ (Index words: Foetal and maternal outcomes, complications, immunosuppressive therapy)
}

\begin{abstract}
Objective To assess the outcome and complications of pregnancy following renal transplantation in Sri Lanka.

Methods Ten pregnancies following transplantation managed between January 1993 and July 1999 by the University Obstetrics and Gynaecology Unit, De Soysa Hospital for Women, Colombo were reviewed.

Results Five women had planned pregnancy with an average duration from transplantation to conception of 2.3 ( \pm 0.2) years; five had an unplanned pregnancy within 12 months of transplantation. All were treated with immunosuppressives, with none developing rejection. In the planned pregnancy group, 3 developed pregnancy induced hypertension and 3 impaired glucose tolerance. All delivered mature healthy babies with an average birth weight of 2.6 $( \pm 0.3) \mathrm{kg}$.

In the unplanned group, 1 developed cholestatic jaundice and delivered a growth retarded baby at 36 weeks. Another developed severe pulmonary oedema at 34 weeks (due to a past myocardial infarction) resulting in a fresh stillbirth. Two others has mid-trimester foetal deaths complicating .
\end{abstract}

severe diabetes mellitus. The conception at 3 months after transplantation developed diabetes mellitus and pregnancy induced hypertension, and delivered a live growth retarded baby. None had deterioration of renal function.

Conclusion Although a successful outcome is possible with stringent pre-pregnancy selection, maternal morbidity and foetal wastage can be high in those without.

\section{Introduction}

Kidney transplantation is the most suitable mode of renal replacement for end-stage renal failure. It is more effective than long term dialysis in restoring fertility and permitting successful pregnancy. Renal, endocrine and sexual function are reported to become normal soon after successful transplantation $(1,2)$.

Reports of high rates of successful pregnancies following transplantation are from centres with well established programs which are located predominantly in the west. Since 1985, 42 women in the childbearing age have undergone live related donor renal transplantation in Sri Lanka (3). This is the first report on pregnancy outcome following transplantation in Sri Lanka.

'Senior Lecturer, and ${ }^{3}$ Professor and Head, Department of Obstetrics and Gynaecology, ${ }^{2}$ Professor and Head, Departments of Clinical Medicine and ${ }^{4}$ Surgery, Faculty of Medicine, University of Colombo (Revised version accepted 25 October 2000). 


\section{Methods}

An analysis of the outcome of pregnancy of women after renal transplantation managed by the University Obstetrics and Gynaecology Unit, De Soysa Hospital for Women, Colombo from January 1993 to December 1998 is presented. They were referred for antenatal care by the Transplant Team of the University of Colombo.

The pregnancies were managed using a standard protocol at a combined antenatal clinic. All patients were clinically evaluated regarding general medical health at antenatal booking. Special consideration was given to blood pressure and cardiac function. The following variables were recorded serially at antenatal follow up: maternal blood pressure, weight gain and well being, maternal infection screen, abdominal ultrasound examination, serum urea, creatinine and electrolyte levels, 24-hour creatinine clearance, urine microscopy and culture, full blood count and a six-point blood glucose series. Obstetric and medical complications detected during pregnancy were managed appropriately. During the antenatal period the patient and her husband were counselled regarding appropriate postpartum family planning methods.

Medical and obstetric indicators determined the mode of delivery. All patients deemed suitable for vaginal delivery were allowed a trial of labour. Steroid cover, antibiotic prophylaxis and epidural analgesia were used for the delivery of all patients. When patients were identified as chronic carriers of hepatitis B, the cord blood was tested for hepatitis B surface antigen, hepatitis B specific immunoglobulin was injected to the baby within 6 hours of birth and active immunisation against hepatitis $B$ was commenced by injecting to the opposite limb.

\section{Results}

The 10 women in their first pregnancy following live related donor renal transplantation were all in the first trimester at antenatal booking. The average maternal age was 31 years (range 21 to 38). Five were planned pregnancies in women who had undergone transplantation 24 to 30 months before conception. The transplantation to conception intervals in the remaining 5 women who had unplanned pregnancies were between 3 and 12 months.

\section{Pregnancy outcomes}

The immunosuppressive therapy in the planned pregnancy group consisted of prednisolone $10 \mathrm{mg}$ daily and azathioprine $1 \mathrm{mg} / \mathrm{kg}$ body weight once daily. Three women were positive for hepatitis B surface antigen, with no evidence of liver dysfunction. Three women developed moderate pregnancy induced hypertension (PIH) in the third trimester, one of whom developed intrauterine foetal growth retardation and reduction in liquor volume confirmed by ultrasound examination. Three developed impaired glucose tolerance (IGT) of pregnancy. All were delivered by elective caesarean section for obstetric reasons. All pregnancies had a successful foetal outcome with live healthy babies weighing 2.2 to $2.9 \mathrm{~kg}$. None of the babies, tested positive for hepatitis $B$ when the umbilical cord blood was evaluated. The baby of the mother with lupus had an uneventful neonatal period. All women opted for sterilisation by tubal ligation following delivery (Table).

In the group with unplanned conceptions, one woman was a primigravida. She developed cholestatic jaundice at 29 weeks of gestation, which persisted up to term. Her serology for viral hepatitis and cytomegalovinus was negative. She required an elective caesarean section at 36 weeks for foetal growth retardation. A live baby weighing $2.1 \mathrm{~kg}$ was delivered. Two others had severe diabetes mellitus. One had type 1 diabetes of 15 years' duration, was in her fifth pregnancy with no living children, and had conceived 11 months after transplantation. She had chronic hypertension, peripheral vascular disease, diabetic neuropathy and retinopathy, and was positive for hepatitis B surface antigen with normal liver function. She developed pregnancy induced hypertension, gross oedema and chronic ulceration of a foot and had a death in utero at 29 weeks' of gestation. The other had steroid induced diabetes, and was the mother of an 8-year old child born before the onset of renal disease. She had undergone transplantation 6 months before conception and was taking prednisolone $20 \mathrm{mg}$ daily. She developed obstructive jaundice, tested positive for hepatitis B surface antigen with no features of hepatic failure. She had an intrauterine death at 29 weeks. The jaundice resolved post-delivery and she underwent sterilisation. Another woman who conceived 6 months following renal transplantation developed heart failure at 36 weeks due to left ventricular dysfunction caused by a previous anterior myocardial infarction. She also tested positive for hepatitis B surface antigen, and developed moderate hypertension. She had spontaneous onset of labour and developed foetal distress: An emergency caesarean section was performed and a fresh stillborn baby weighing $2.2 \mathrm{~kg}$ was delivered She underwent surgical sterilisation. The woman who conceived 3 months after renal transplantation was in her third pregnancy with no living children. She developed moderate pregnancy induced hypertension and severe diabetes requiring insulin therapy. She underwent an elective caesarean section at 36 weeks and a live growth retarded baby weighing $1.9 \mathrm{~kg}$ was delivered. The immunosuppressive therapy in this group of women consisted of prednisolone $20 \mathrm{mg}$ daily, azathioprine $2 \mathrm{mg} / \mathrm{kg}$ and cyclosporine $10 \mathrm{mg} / \mathrm{kg}$ daily.

\section{Discussion}

More than 2000 pregnancies following renal transplantation have been reported, predominantly from the western world (4-8). There are no reports from South Asia. It is estimated that 1 in 50 women of child-bearing age with a functioning renal transplant becomes pregnant. Nearly $30 \%$ of conceptions following transplantation abort spontaneously in the first trimester, but more than $90 \%$ of those that survived the first trimester have had a successful outcome (9). A much higher rate of fertility was observed in this series, with 10 out of $\mathbf{4 2}$ women in the child-bearing age group becoming pregnant. Moreover, this figure may be an underestimate in view of probable unreported early miscarriages. The high fertility reflects the desire of Sri Lankan women following renal transplantation to bear children or unmet family planning needs. 
Table 1. Patient data in the planned and unplanned pregnancy groups

\begin{tabular}{|c|c|c|c|c|}
\hline $\begin{array}{l}\text { Age } \\
\text { (Years) }\end{array}$ & Parity & $\begin{array}{l}\text { Previous } \\
\text { obstetric } \\
\text { problems }\end{array}$ & $\begin{array}{l}\text { Specific medical/ } \\
\text { renal disorder }\end{array}$ & $\begin{array}{l}\text { Pregnancy } \\
\text { complication }\end{array}$ \\
\hline \multicolumn{5}{|c|}{ Planned pregnancies } \\
\hline 34 & P1 & Infertility for 4 years & & PIH \\
\hline $\begin{array}{l}29 \\
36\end{array}$ & $\begin{array}{l}\mathrm{Pl} \\
\mathrm{P3}\end{array}$ & $\begin{array}{l}\text { Nil } \\
2 \text { foetal deaths complicating }\end{array}$ & Lupus nephritis & $\begin{array}{l}\text { IGT + PIH } \\
\text { IGT + PIH }\end{array}$ \\
\hline & & severe hypertension & & \\
\hline 30 & $\begin{array}{l}\text { P2 } \\
\text { P2 }\end{array}$ & First trimester abortion & & IGT \\
\hline
\end{tabular}

Unplanned pregnancies

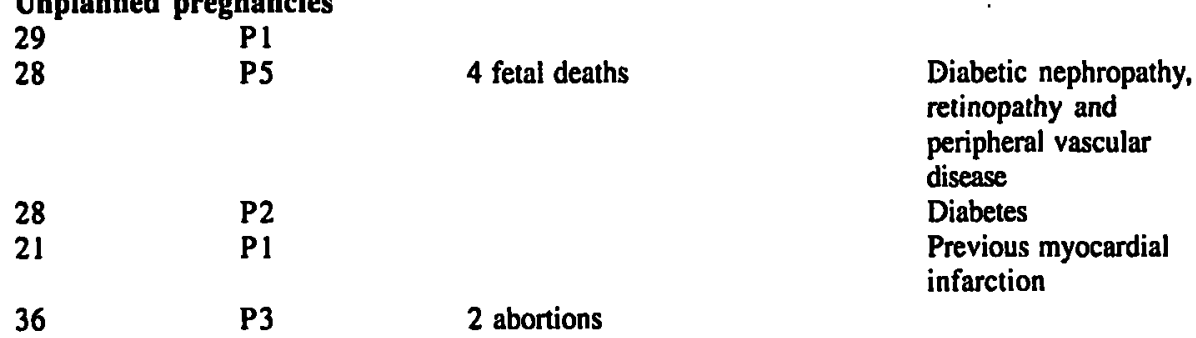

Cholestasis + PIH

Severe PIH + IUD

retinopathy and

peripheral vascular

disease

Cholestasis + IUD

Heart failure, moderate

PIH, and IUD

Moderate PIH + diabetes

(PIH = pregnancy induced hypertension, IGT = impaired glucose tolerance, IUD = intrauterine death)

Survival figures indicate that $80 \%$ of recipients of kidneys from live related donors are alive at 5 years, with more than $50 \%$ expected to survive for at least 10 years (10). If graft function is maintained at 2 years the chances of allograft survival at 5 and 10 years is high (11). When a woman with a transplanted kidney becomes pregnant, a major concern is that the mother may not survive or remain well enough to rear the child. Indeed, about $10 \%$ of these women may be dead within 7 years of pregnancy.

Although in this series a successful outcome was achieved in $70 \%$, there was a high maternal morbidity and foetal wastage. It is recommended to wait for 18 to 24 months after renal transplant to allow time for recovery from surgery, for graft function to stabilise and for the immunosuppression to reach maintenance levels. Other recommendations for starting a pregnancy are that the woman is normotensive with minimal or no proteinuria, has no evidence of graft rejection or pelvicalyceal distension, and has a stable creatinine less than $150 \mu \mathrm{mol} / 1$ (12). Only $50 \%$ of women in this series met all these requirements. Although the number is small in this series, its results show that if these criteria are fulfilled much less complications would occur during pregnancy.

The common complications that occur among poorly selected patients include pre-eclampsia, gestational diabetes, foetal growth retardation and maternal cardiac and hepatic dysfunction. The high prevalence of hepatitis B carrier status is another factor that needs to be considered in the evaluation for fitness, although it is not a barrier for a planned conception. The high rate of caesarean section in this series differs from that previous reports. The indications for caesarean section in this series were chiefly poor previous obstetric outcome, advanced maternal age and foetal growth retardation. Our policy has been to comply with the patient's request for sterilisation at the time of a successful caesarean delivery. The management of women of child-bearing age who undergo successful renal transplantation should include a keen awareness of their improved fertility and associated complications, and the careful selection, timing and appropriate management of pregnancy.

\section{References}

1. Merkatz IR, Schwartz GH, David DS, Stenzel KH, Riggio RR, Whitsell JC. Resumption of female reproductive function following renal transplantation. Journal of the American Medical Association 1971, 216: 1749-54.

2. British Medical Journal (Editorial) Effect of transplantation on non-renal effects of renal failure. 1981; 284: 221-2.

3. Country report Sri Lanka. Proceedings of $3^{\text {rd }}$ International Congress of the Nephrology, Urology and Transplantation Society of SAARC Countries, March 1999: 16-7.

4. Muimead N, Sabharwal AR, Reider MJ, Lazarovits AI, Hollomby DJ. The outcome of pregnancy following renal transplantation - the experience of a single centre. Transplantation 1992; 54: 429-32.

5. Cararach V, Carmona F, Monleon PJ, Andreu J. Pregnancy after renal transplantation : 25 years' experience in Spain. British Journal of Obstetrics and Gynaecology 1993; 100: 122-5.

6. To WW, Lam KS, Chan YM. Pregnancy following renal transplantation: the experience in Hong Kong. Joumal of Obstetrics and Gynaecology 1995; 21 : 263-7.

7. Barr J, Wittenberg C, Hod M, Lustig S, Kaplan B, et al. Pregnancy outcome in renal allograft recipients in Israel. Israel Journal of Medical Sciences 1996; 32: 1183-5.

8. British Medical Joumal (Editorial) Pregnancy after renal transplantation 1976; 1: 733-4.

9. Davidson JM, Milne JE. Pregnancy and renal transplantation. British Joumal of Urology 1997; 80: 29-32.

10. Cecka JM, Terasaki PI. The UNOS Scientific Renal Transplant Registry. In: Terasaki JPI, Cecka JM, eds. Clinical Transplants 1995. Los Angeles: Tissue Typing Laboratory, 1996: 1-3.

11. Davidson J M. Pregnancy in renal allograft recipients: prognosis and management. Kidney International 1987; 27: 74-9.

12. Davidson JM, Balylis $C$. Pregnancy in patients with underlying renal disease. S Cameron, AM Davidson, Jentierrejnunseld J, KGTC David, R Eherhard, eds. Oxford Textbook of Nephrology. Oxford: Oxford University Press, 1949: 52-9. 